\title{
Mechanical Thrombectomy with Solitaire Stent Retrieval for Acute Cardioembolic Stroke
}

\author{
Hokyun Han, M.D., ${ }^{1}$ Hyunho Choi, M.D., ${ }^{1}$ Keun-Tae Cho, M.D., ${ }^{1,2}$ Byong-Cheol Kim, M.D. ${ }^{1,2}$ \\ Department of Neurosurgery, Dongguk University Ilsan Hospital, Goyang, Korea \\ Department of Neurosurgery, ${ }^{2}$ Dongguk University College of Medicine, Seoul, Korea
}

Objective : Few studies have reported the outcome of mechanical thrombectomy with Solitaire stent retrival (MTSR) in subtypes of acute ischemic stroke. The purpose of this study was to evaluate the efficacy and result of MTSR in acute cardioembolic stroke.

Methods : Twenty consecutive patients with acute cardioembolic stroke were treated by MTSR. The angiographic outcome was assessed by thrombolysis in cerebral infarction $(\mathrm{TICl})$ grade. $\mathrm{TICl}$ grade $2 \mathrm{a}, 2 \mathrm{~b}$, or 3 with a measurable thrombus that was retrieved was considered as a success when MTSR was performed in the site of primary vessel occlusion, and TICl grade $2 \mathrm{~b}$ or 3 was considered as a success when final result was reported. Clinical and radiological results were compared between two groups divided on the basis of final results of MTSR. Persistent thrombus compression sign on angiogram was defined as a stenotic, tapered arterial lumen whenever temporary stenting was performed. The clinical outcomes were assessed by the modified Rankin Scale (mRS) at 3 months.

Results : The failure rate of MTSR was 20\% (4/20) and other modalities, such as permanent stenting, were needed. Final successful recanalization ( $\mathrm{TICl}$ grade $2 \mathrm{~b}$ or 3 ) was $80 \%$ when other treatments were included. The rate of good outcome (mRS $\leq 2)$ was $35 \%$ at the 3-month follow-up. Failure of MTSR was significantly correlated with persistent thrombus compression sign $(p=0.001)$.

Conclusion : Some cases of cardioembolic stroke are resistant to MTSR and may need other treatment modalities. Careful interpretation of angiogram may be helpful to the decision.

Key Words : Intracranial embolism · Mechanical thrombolysis.

\section{INTRODUCTION}

Ischemic stroke is a major cause of death in developed countries. Intravenous thrombolysis with recombinant tissue plasminogen activator (IV rt-PA) has been proven to be effective for the treatment of acute ischemic stroke. However, IV rtPA has limited ability to recanalize a large vessel occlusion $(\mathrm{LVO})^{21,34)}$. Mechanical thrombectomy with Solitaire stent re- trieval (MTSR) is a simple procedure that has been reported to have excellent recanalization rates of $\mathrm{LVO}^{9,18)}$. The efficacy of MTSR can differ according to the etiology of ischemic stroke. TOAST study has been widely used and denotes five subtypes of ischemic stroke ${ }^{1)}$. Clinical features that suggest the diagnosis of cardioembolic stroke includes sudden onset to maximal neurologic deficit ( $<5$ minutes) and altered consciousness at onset $^{3)}$. However, the clinical diagnosis of cardioembolic

- Received : July 7, 2016 • Revised : November 22, 2016 •Accepted : March 27, 2017

- Address for reprints : Byong-Cheol Kim, M.D.

Department of Neurosurgery, Dongguk University Ilsan Hospital, 27 Dongguk-ro, Ilsandong-gu, Goyang 10326, Korea Tel : +82-31-961-7324, Fax : +82-31-961-7327, E-mail : han850317@naver.com

This is an Open Access article distributed under the terms of the Creative Commons Attribution Non-Commercial License (http://creativecommons.org/licenses/by-nc/4.0) which permits unrestricted non-commercial use, distribution, and reproduction in any medium, provided the original work is properly cited. 
stroke is difficult. Several systems of classification of ischemic stroke have been devised ${ }^{1,13}$, but they share core etiologic catergorization. Clinical and radiological outcomes after MTSR of acute cardioembolic stroke have not been reported. In this study, we assessed the outcome of MTSR in cardioembolic stroke.

\section{MATERIALS AND METHODS}

This retrospective study had institutional ethics committee approval. Two neurointerventionists participated in the treatments.

\section{Patient selection}

A total of 46 consecutive patients with ischemic stroke due to LVO were treated using intra-arterial procedures from May 2011 to March 2015. Twenty patients were diagnosed with acute cardioembolic stroke. On admission, neurologic assessments were performed using the National Institutes of Health Stroke Scale (NIHSS). All patients underwent non-contrast brain computed tomography (CT). Eligible patients were treated with IV rt-PA and the association of multisection CT angiography (CTA), and perfusion CT (PCT) was performed to confirm immediate recanalization of the LVO 1 hour after IV rt-PA ${ }^{31}$. Non-eligible patients for IV rt-PA received CTA and PCT, or brain magnetic resonance imaging (MRI) and magnetic resonance angiography (MRA). If large vessels were still occluded, intra-arterial procedures would be performed. Cardioembolic stroke was diagnosed on luminal status of contralateral internal carotid artery (ICA) and other major vessels, and arrhythmia such as atrial fibrillation and/or congestive heart failure and/or valvular heart disease ${ }^{1)}$. The inclusion criteria of this study were as follows : 1) baseline NIHSS score $\geq 8$; 2) large vessel occlusion; and 3) confirmed atrial fibrillation and/or congestive heart failure and/or valvular heart disease at admission. Large vessels were ICA, M1 segment of middle cerebral artery (MCA), and basilar artery (BA). The exclusion criteria were as follows : 1) the Alberta Stroke Program Early CT Score (ASPECTS) $<5$ and 2 ) any grade stenosis of intracranial and/or extra-cranial arteries using NASCET criteria. After MTSR, immediate postprocedural brain CT and 24-hour brain MRI and MRA was performed.

\section{Interventional procedures}

All procedures were performed under general anesthesia or sedation. For the anterior circulation, a guiding catheter was introduced into the cervical ICA as distal as possible. A Shuttle guide sheath (Shuttle-SL; Cook, Bloomington, IN, USA) was used to support the guiding catheter in some cases. The guiding catheter was continuously flushed with heparinized normal saline. Solitaire stent (Covidien, Irvine, CA, USA) for MTSR was selected in accordance with target vessel diameter; the stent diameter was 1 or $2 \mathrm{~mm}$ larger than that of the target vessel. A microcatheter (Prowler Select Plus [Cordis, Dublin, $\mathrm{OH}$, USA] or Rebar ${ }^{\mathrm{TM}} 27$ [Covidien]) was navigated distal to the point of occlusion and superselective angiography was carried out to evaluate the status of distal vasculature. The Solitaire stent was advanced and was temporarily deployed for 5 to 10 minutes to allow full expansion. After Solitaire stent deployment, cerebral angiography was performed to evaluate the status of the occluded vessel. During extraction of the thrombus, the deployed Solitaire stent and the microcatheter were pulled back as a single unit. Manual compression of cervical carotid artery was performed, if possible. In cases of posterior circulation stroke, the process of MTSR was similar to that of anterior circulation stroke.

If cerebral angiography presented no effect after trials of MTSR, other treatment modalities, such as permanent stenting or balloon angioplasty, were considered. When the occluded vessel was recanalized, another angiographic run was performed to assess the status of distal vessels. If a major vessel distal to primary occlusion site was occluded, another MTSR was also performed.

\section{Outcome measure and analysis}

The thrombus that occluded the vessel should be located at either inside or outside of the deployed stent. Thrombus that was completely outside outlines the relatively smooth curve of the deployed stent. Thus, a cerebral angiogram reveals a tapered vascular stenosis at the point of occlusion during temporary stenting, and it is presumed that the thrombus is not entrapped inside the stent but compressed by the stent. Presently, this was designated as a thrombus compression (TC) sign (Fig. 1). Thrombus that was partially or totally inside the stent could be outlined as a bulging contour through stent struts. Cerebral angiography presents near occlusion or stenosis with non-tapered irregular lumen at the target vessel after 
full deployment of the stent, and it is reasonable to assume that the thrombus are totally or partially entrapped inside the stent. This represented a thrombus entrapment (TE) sign (Fig. 2). Angiographic signs during each time of temporary stenting were analyzed. Inter-observer agreement was assessed and Kappa coefficient was measured as 0.68 . It was considered to be substantial agreement (Kappa 0.61-0.80) ${ }^{32)}$. Primary occlusion points were the ICA, M1, and BA. Persistent TC signs were defined as TC signs after each session. The thrombolysis in cerebral infarction (TICI) scale was used to evaluate angiographic intracranial flow. After each session, MTSR failure in the site of primary vessel occlusion was defined when cerebral angiography revealed no improvement of TICI grade (TICI 0, 1) and no measurable clot was extracted. Successful MTSR was defined as recanalization of TICI grade $2 \mathrm{a} / \mathrm{b}$ or 3 after MTSR. Distal vessel occlusion was defined as a vessel occlusion independent of the primary vessel occlusion. Final successful recanalization was defined as TICI grade $2 \mathrm{~b}$ or 3 at the end of the whole procedure because the additional MTSR of distal vessel occlusion could be required. Clinical outcome was assessed at 3 months using the modified Rankin Scale (mRS). Good clinical outcome was defined as a mRS score $0-2$. We divided the patients into two groups on the basis of the results (success or failure) of MTSR in the primary vessel
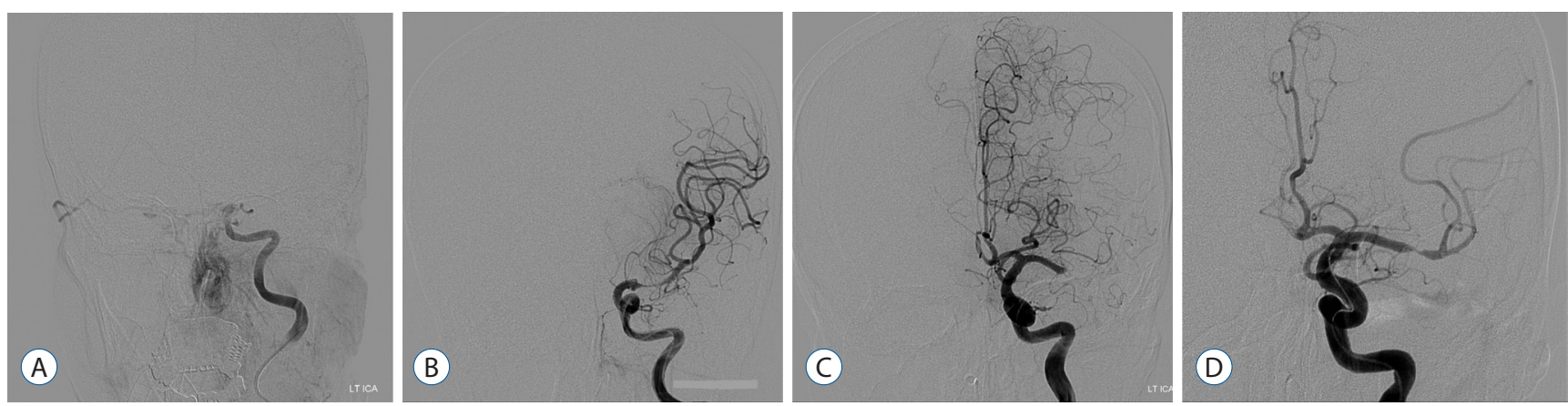

Fig. 1. Thrombus compression sign is defined as a tapered vascular stenosis when temporary stenting. (A and B) are angiograms of case 3 . A : Initial angiogram shows left ICA terminus occlusion. $B$ : Angiogram after temporary stenting shows a tapered stenosis which mimics true stenosis of left MCA. ( $C$ and $D$ ) are angiograms of case 13. C : Initial angiogram shows left M1 occlusion. D : Angiogram after temporary stenting reveals a pseudostenosis of left MCA. ICA : internal carotid artery, MCA : middle cerebral artery.
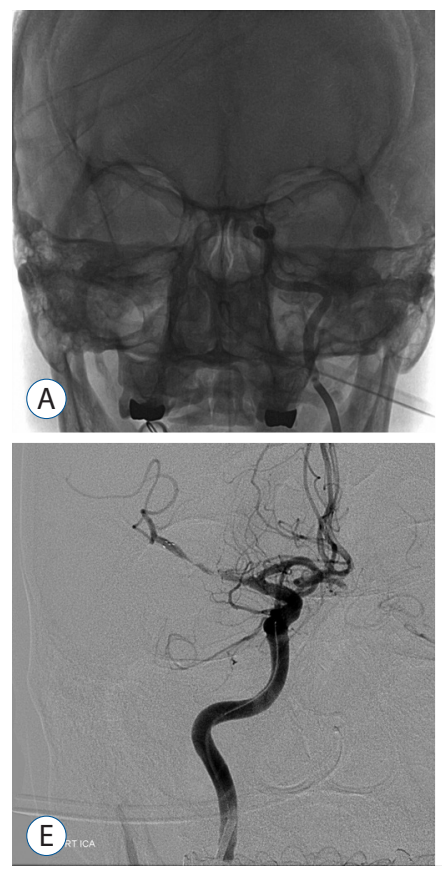
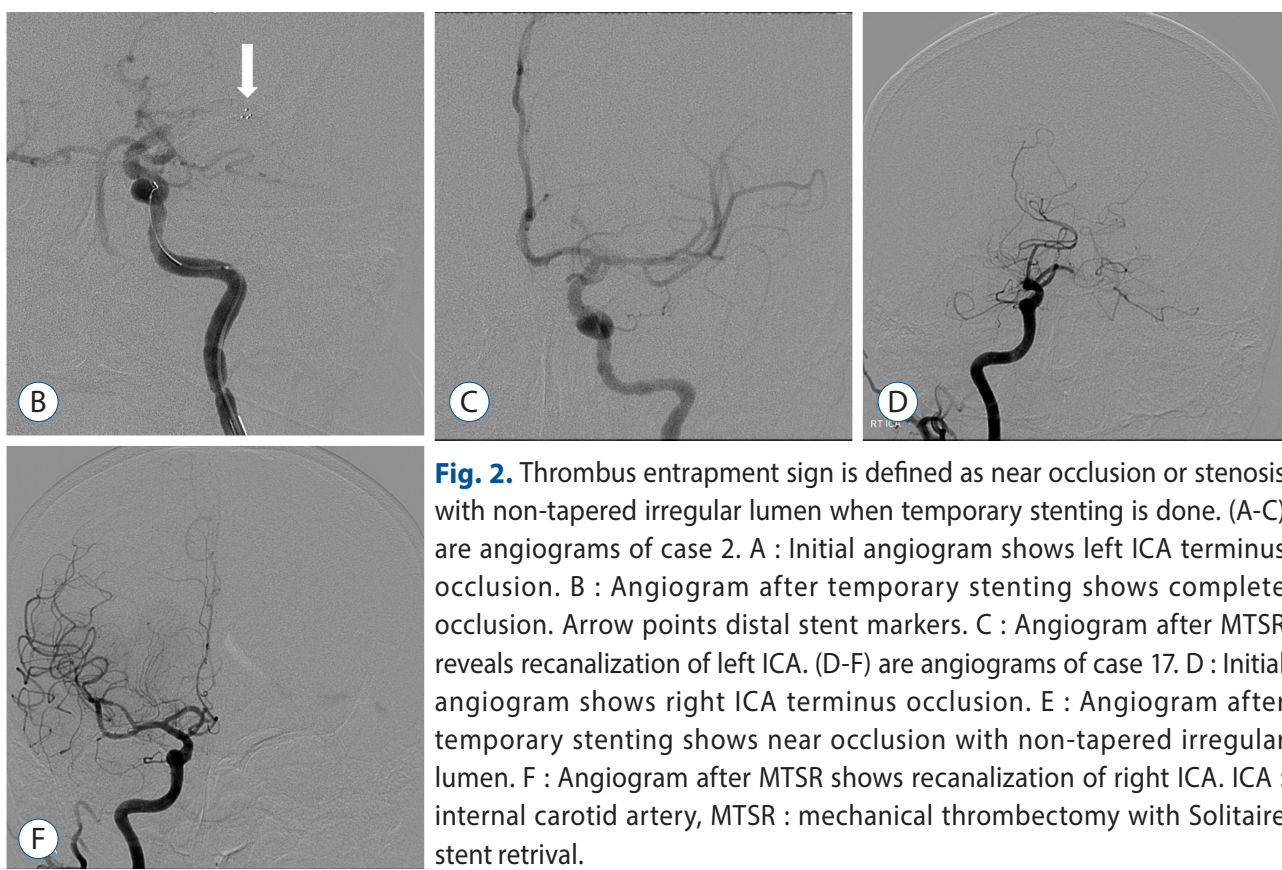

Fig. 2. Thrombus entrapment sign is defined as near occlusion or stenosis with non-tapered irregular lumen when temporary stenting is done. (A-C) are angiograms of case 2 . $A$ : Initial angiogram shows left ICA terminus occlusion. B : Angiogram after temporary stenting shows complete occlusion. Arrow points distal stent markers. C : Angiogram after MTSR reveals recanalization of left ICA. (D-F) are angiograms of case 17. D : Initial angiogram shows right ICA terminus occlusion. $E$ : Angiogram after temporary stenting shows near occlusion with non-tapered irregular lumen. F : Angiogram after MTSR shows recanalization of right ICA. ICA : internal carotid artery, MTSR : mechanical thrombectomy with Solitaire stent retrival. 


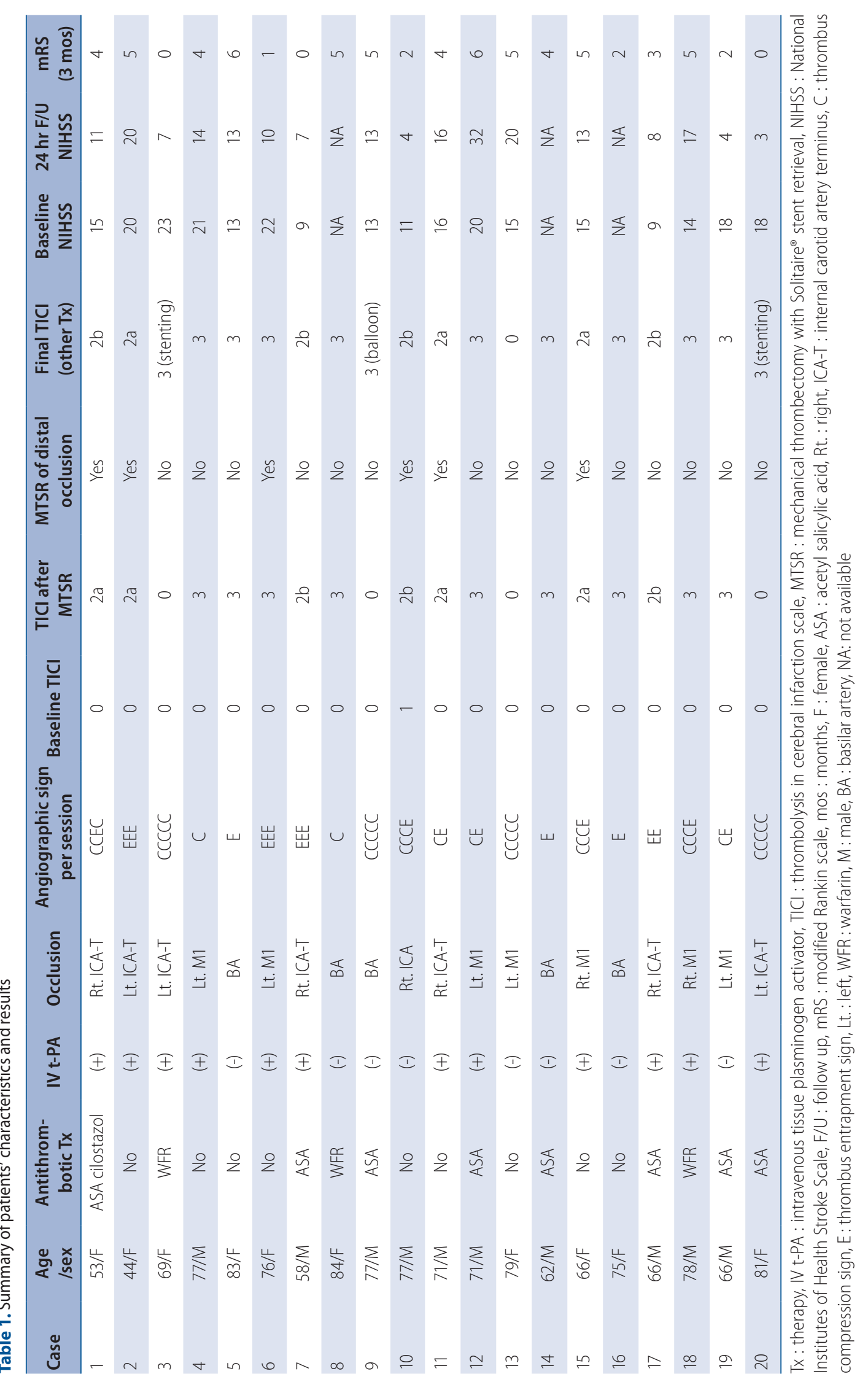


occlusion and compared factors between two groups (Table 1). Statistical analysis was conducted by using the Statistical Package for the Social Sciences, version 12 (SPSS Inc., Chicago, IL, USA). The Fisher exact test and the Mann-Whitney U test were used to evaluate the relationship between factors and the results of MTSR. Statistical significance was accepted for $p<0.05$.

\section{RESULTS}

Twenty consecutive patients (10 men and 10 women) who suffered acute cardioembolic stroke were treated with MTSR. Eleven patients (55\%) had taken prophylactic antithrombotic medications (aspirin [n=7]; aspirin+cilostazol [n=1]; warfarin $[n=3])$ before acute stroke. The mean age of the patients was 71 years (range, 44-84 years). The median baseline NIHSS score was 15 (range, 9-23). IV rt-PA was performed in 12 $(60 \%)$ patients. Sites of primary vessel occlusion were ICA in 8 , MCA (M1) in 7, and BA in 5 cases. The average time from femoral puncture to the end of the procedure was 84 minutes (range, 30-180 minutes). Recanalization (TICI 2b, 3) was successful in $80 \%(16 / 20)$ of the patients at the end of the whole procedure that included other treatment modalities. The rate of reperfusion hemorrhage was $10 \%(2 / 20)$. At the 3 months follow-up, 35\% (7/20) of patients had a good clinical outcome (mRS 0-2).

The failure rate of MTSR in the primary vessel occlusion was $20 \%(4 / 20)$. IV rt-PA, prophylactic antithrombotic medication, complications, and good clinical outcome were not significantly associated with failure of MTSR. The presence of angiographic TE sign was significantly correlated with success of MTSR ( $p=0.003$ ). The failure of MTSR was significantly associated with persistent TC signs $(p=0.001)$. The rate of secondary MTSR of distal vessel occlusion was 30\% (6/20).

\section{DISCUSSION}

IV rt-PA for acute ischemic stroke is effective, but the recanalization rates of LVO in previous studies ranged from $21 \%$ to $56 \%$, which were not satisfactory ${ }^{6,34)}$. MTSR is an effective method for recanalization of $\mathrm{LVO}^{9,18)}$. MTSR is simple, but rates of successful recanalization were variable from $26 \%$ to $89 \%{ }^{9,15,18)}$. The effectiveness of MTSR can be commonsensically summarized into the following steps after stent deployment. First, the thrombus is cut through with struts of deployed Solitaire stent and is partially or totally entrapped in the stent lumen. Second, the entrapped thrombus is stuck or attached to the struts and is removed with the stent. Both steps can be strongly influenced by variations in mechanical properties of the thrombus, which provides hardness and an adhesive force against the vessel wall. Embolized thrombi can have different chronological ages ${ }^{11,21)}$. Hardness is positively correlated with chronological aging, which is determined by the organizing stages ${ }^{8,11,14)}$. Therefore, thrombi could have variable hardness and elasticity ${ }^{8,11,14,17,19,20,22,23)}$. Thrombi also have internal heterogeneity of stages, but may be categorized in two distinct patterns : a hard, organized thrombus in which all elements are densely integrated, and a soft, fresh thrombus in which various elements are loosely cross-linked ${ }^{11,14,20,23,24)}$. The variable hardness of thrombi against radial force of Solitaire stent can lead to different radiologic signs, which may be divided into dichotomous patterns. The radiological TC sign means a failure of the first step while MTSR is performed. Most cases of successful MTSR presented only TE signs or combination of TC and TE signs on serial sessions. This reflected the heterogeneity of the organizing stages within the thrombus. Presently, we included LVO due to non-atherosclerotic, cardio-embolic origin, because it is possible for MTSR to dissect the atherosclerotic vessel ${ }^{2)}$ and the stenotic lesion of the vessel can be mistaken as persistent TC signs. The presence of TE sign during MTSR was significantly correlated with success of MTSR $(p=0.003)$ and failure of MTSR was associated with persistent TC signs $(p=0.001)$.

Failure of the second step during MTSR can be influenced by the adhesion force between the thrombus and the vessel wall. The embolized thrombus adheres to the vessel wall in accordance with platelet adhesion and the transition from temporay adhesion to stable adhesion occurs within minutes $^{5,10,26-28)}$. The adhesion force of the thrombus can vary in accordance with platelet adhesion force, which is determined by thrombus burden and platelet adhesion stability ${ }^{7,25,29,33)}$. Two cases presented single TC sign but the thrombi were easily removed with a session of MTSR. The thrombus can be dragged, if the adhesion force of the thrombus is too weak to resist; this distinguished the results between persistent TC signs and single TC sign. No distal thromboembolization oc- 

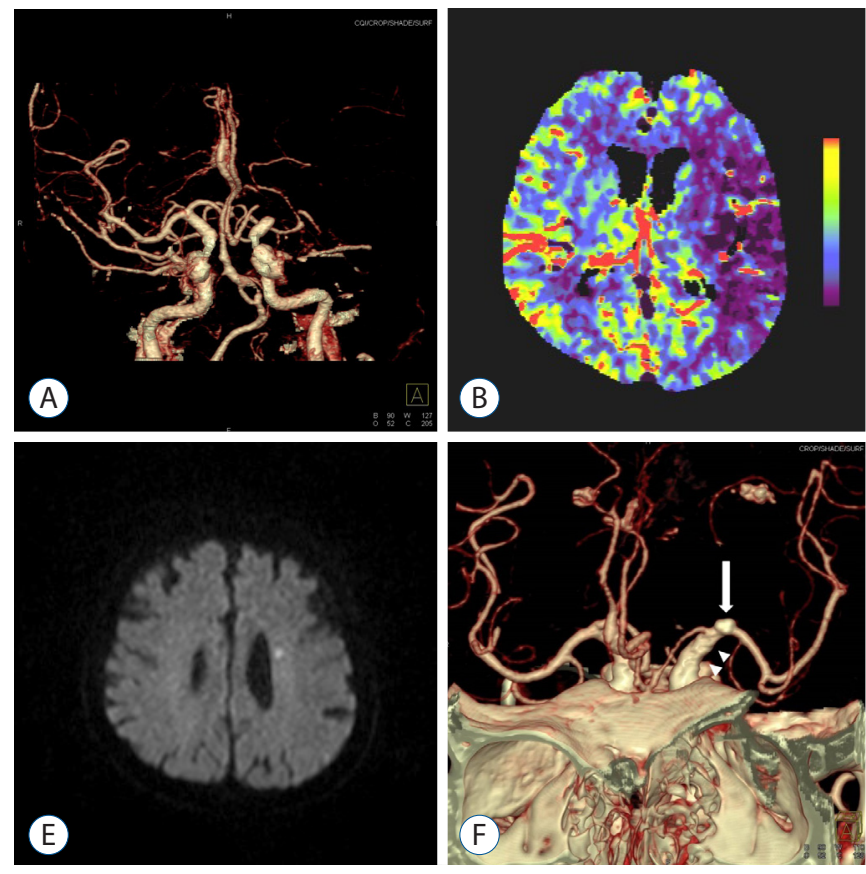

(c)
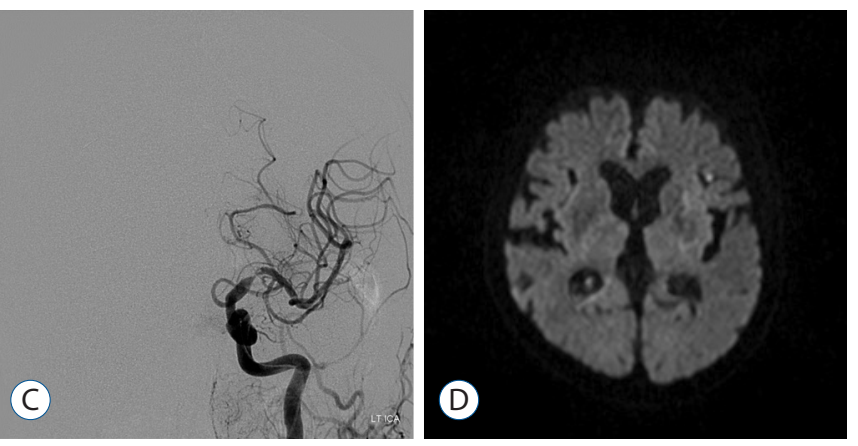

Fig. 3. Case of permanent stenting (case 20). A : Initial CTA shows left ICA terminus occlusion. B : Perfusion CT presents decreased CBF in the left hemisphere. $C$ : Angiogram after temporary stenting reveals a tapered stenosis of left ICA terminus. D and E : Diffusion MR after 24 hours shows only minimal cerebral infarcts. F : CTA after 1 month reveals total lysis of the thrombus. Arrowheads points strut of the stent and arrow indicates distal markers of the stent. CTA : computed tomography angiography, ICA : internal carotid artery, CT : computed tomography, CBF : cerebral blood flow, MR: magnetic resonance.

curred in patients with persistent TC signs, which was treated by permanent stenting. Distal thromboemolization could occur in the thrombus which was fresh, friable, and easily entrapped in the deployed Solitaire stent. Permanent stenting after failure of MTSR would be a paradox, which had good results in our series. The thrombus, which is solid and strongly adhered to the vessel, can be easily treated by permanent stenting.

If neuro-interventionists could predict characteristics of the thrombus during MTSR, the dilemma of whether to perform MTSR or permanent stenting could be solved. In our study, all cases of failed MTSR presented persistent TC signs and demanded other treatment modalities. Cases of persistent TC signs lasting over 25 minutes could be treated with permanent stenting. Some studies reported the good result of permanent stenting after IV thrombolysis and/or mechanical thrombectomy; recanalization rates ranged from $79 \%$ to $100 \%{ }^{12,16,30)}$. Recently, Baek et al. ${ }^{4}$ achieved good clinical outcomes of permanent stenting for failed MTSR in anterior circulation (mRS $0-2$ of stenting vs. non-stenting : $35 \%$ vs. $7 \%$ ). In our study, half (2/4) of patients with failed MTSR received permanent stenting; both had excellent outcomes (Fig. 3). In the other two patients, in whom occlusion occurred at bifurcation (MCA, BA), another modality was not performed in one case (MCA bifurcation occlusion) and balloon angioplasty was used in the other case (BA bifurcation occlusion). In our early experience, we doubted the efficacy of permanent stenting at bifurcation sites (MCA, BA) and did not try to perform permanent stenting. After permanent stenting, glycoprotein IIb/ IIIa Inhibitor, which is bolus injected intra-arterially and maintains for at least 24 hours is effective for prevention of acute in-stent thrombosis ${ }^{4,30)}$. In our cases of stenting, antithrombotic medication was administered before stroke occurrence and IV rt-PA was used at Emergency room. Postprocedural medication with aspirin and clopidogrel was initiated after 24 hours.

This study has some limitations. The number of the patients is small; further evaluation of a larger cohort will be necessary. The efficacy of MTSR or permanent stenting at arterial bifurcations, such as MCA bifurcation, should be studied. Relationship between angiographic sign and distal thromboembolization should also be evaluated.

\section{CONCLUSION}

MTSR is an efficient method for recanalization of LVO in cardioembolic stroke, but some resistant cases do occur. Persistent TC signs may predict failure of MTSR and another modality, such as permanent stenting, may be needed. 


\section{References}

1. Adams HP Jr, Bendixen BH, Kappelle LJ, Biller J, Love BB, Gordon DL, et al. : Classification of subtype of acute ischemic stroke. Definitions for use in a multicenter clinical trial. TOAST. Trial of Org 10172 in Acute Stroke Treatment. Stroke 24 : 35-41, 1993

2. Akins PT, Amar AP, Pakbaz RS, Fields JD; SWIF Investigators : Complications of endovascular treatment for acute stroke in the SWIFT trial with solitaire and Merci devices. AJNR Am J Neuroradiol 35 : 524-528, 2014

3. Arboix A, Alió J : Cardioembolic stroke: clinical features, specific cardiac disorders and prognosis. Curr Cardio Rev 6 : 150-161, 2010

4. Baek JH, Kim BM, Kim DJ, Heo JH, Nam HS, Yoo J : Stenting as a rescue treatment after failure of mechanical thrombectomy for anterior circulation large artery occlusion. Stroke 47 : 2360-2363, 2016

5. Baruch D : Platelet--vessel wall interactions. Therapie 5 : 371-378, 2006

6. Bhatia R, Hill MD, Shobha N, Menon B, Bal S, Kochar P, et al. : Low rates of acute recanalization with intravenous recombinant tissue plasminogen activator in ischemic stroke : real-world experience and a call for action. Stroke 41 : 2254-2258, 2010

7. Chueh J, Kuhn AL, Mehra M, Feula G, Wakhloo AK, Gounis MJ : Embolus adhesion to activated endothelium after embolization: a parameter to predict outcomes of mechanical thrombectomy in acute ischemic stroke. Stroke 43 : A3750, 2012

8. Chueh JY, Wakhloo AK, Hendricks GH, Silva CF, Weaver JP, Gounis MJ : Mechanical characterization of thromboemboli in acute ischemic stroke and laboratory embolus analogs. AJNR Am J Neuroradiol 32 : 12371244, 2011

9. Costalat V, Machi P, Lobotesis K, Maldonado I, Vendrell JF, Riquelme $C$, et al. : Rescue, combined, and stand-alone thrombectomy in the management of large vessel occlusion stroke using the solitaire device: a prospective 50-patient single-center study: timing, safety, and efficacy. Stroke 42 : 1929-1935, 2011

10. Esmon CT : Basic mechanisms and pathogenesis of venous thrombosis. Blood Rev 23 : 225-229, 2009

11. Fineschi V, Turillazzi E, Neri M, Pomara C, Riezzo I : Histological age determination of venous thrombosis: a neglected forensic task in fatal pulmonary thrombo-embolism. Forensic Sci Internat 186 : 22-28, 2009

12. Gralla J, Brekenfeld C, Mordasini P, Schroth G : Mechanical thrombolysis and stenting in acute ischemic stroke. Stroke $43:$ 280-285, 2012

13. Han SW, Kim SH, Lee JY, Chu CK, Yang JH, Shin HY, et al. : A new subtype classification of ischemic stroke based on treatment and etiologic mechanism. Eur Neurol 57 : 96-102, 2007

14. Karšaj I, Humphrey JD : A mathematical model of evolving mechanical properties of intraluminal thrombus. Biorheology 46 : 509-527, 2009

15. Kim TK, Rhim JK, Lee CJ, Oh SH, Chung BS : The limitations of thrombectomy with SolitaireTM $A B$ as first-line treatment in acute ischemic stroke: a single center experience. J Cerebrovasc Endovasc Neurosurg 14 : 203-209, 2012
16. Levy El, Siddiqui AH, Crumlish A, Snyder KV, Hauck EF, Fiorella DJ, et al. : First Food and Drug Administration-approved prospective trial of primary intracranial stenting for acute stroke: SARIS (stent-assisted recanalization in acute ischemic stroke). Stroke 40 : 3552-3556, 2009

17. Liebeskind DS, Sanossian N, Yong WH, Starkman S, Tsang MP, Moya AL, et al. : CT and MRI early vessel signs reflect clot composition in acute stroke. Stroke 42 : 1237-1243, 2011

18. Machi P, Costalat V, Lobotesis K, Maldonado IL, Vendrell JF, Riquelme C, et al. : Solitaire FR thrombectomy system: immediate results in 56 consecutive acute ischemic stroke patients. J Neurointerv Surg $4: 62$ 66, 2012

19. Marder VJ, Chute DJ, Starkman S, Abolian AM, Kidwell C, Liebeskind D, et al. : Analysis of thrombi retrieved from cerebral arteries of patients with acute ischemic stroke. Stroke 37 : 2086-2093, 2006

20. Mehta BP, Nogueira RG : Should clot composition affect choice of endovascular therapy? Neurology 79(13 Suppl 1) : S63-S67, 2012

21. National Institute of Neurological Disorders and Stroke rt-PA Stroke Study Group : Tissue plasminogen activator for acute ischemic stroke. N Engl J Med 333 : 1581-1587, 1995

22. Niesten JM, van der Schaaf IC, van Dam L, Vink A, Albert Vos J, Schonewille WJ, et al. : Histopathologic composition of cerebral thrombi of acute stroke patients is correlated with stroke subtype and thrombus attenuation. PLoS One 9 : e88882, 2014

23. Nogueira RG, Sukavaneshvar S, Rabinov JD, Dabus G, Yoo AJ, Buonanno FS, et al. : Scanning electron microscopy analysis of thromboembolic material retrieved from cerebral and cervical arteries of patients with acute ischemic stroke: Abstracts from the 2008 international stroke conference. Stroke 39 : 562, 2008

24. Nosaka M, Ishida Y, Kimura A, Kondo T : Time-dependent organic changes of intravenous thrombi in stasis-induced deep vein thrombosis model and its application to thrombus age determination. Forensic Sci Int 195 : 143-147, 2010

25. Romeo G, Martinez ML, Maroto J, Felez J : Blood clot simulation model by using the Bond-Graph technique. ScientificWorldJournal 2013 : 519047, 2013

26. Ruggeri ZM : Platelets in atherothrombosis. Nat Med 8 : 1227-1234, 2002

27. Ruggeri ZM, Mendolicchio GL : Adhesion mechanisms in platelet function. Circ Res 100 : 1673-1685, 2007

28. Ruggeri ZM, Orje JN, Habermann R, Federici AB, Reininger AJ : Activation-independent platelet adhesion and aggregation under elevated shear stress. Blood 108 : 1903-1910, 2006

29. Shiozaki S, Ishikawa KL, Takagi $S$ : Numerical study on platelet adhesion to vessel walls using the kinetic Monte Carlo method. JBSE $7: 275$ 283, 2012

30. Stampfl S, Hartmann M, Ringleb PA, Haehnel S, Bendszus M, Rohde S : Stent placement for flow restoration in acute ischemic stroke: a singlecenter experience with the Solitaire stent system. AJNR Am J Neuroradiol 32 : 1245-1248, 2011

31. Tan JC, Dillon WP, Liu S, Adler F, Smith WS, Wintermark M : Systematic comparison of perfusion-CT and CT-angiography in acute stroke pa- 
tients. Ann Neurol 61 : 533-543, 2007

32. Viera AJ, Garrett JM : Understanding interobserver agreement: the kappa statistic. Fam Med 37 : 360-363, 2005

33. Ware JA, Heistad DD : Platelet-endothelium interactions. N Engl J Med
$328: 628-635,1993$

34. Zangerle A, Kiechl S, Spiegel M, Furtner M, Knoflach M, Werner $P$, et al. : Recanalization after thrombolysis in stroke patients: predictors and prognostic implications. Neurology 68 : 39-44, 2007 